\title{
The frequency of FV G1691A and PT G20210A mutations in an Albanian population
}

\author{
Arnavut popülasyonunda FV G1691A ve PT G20210A mutasyonu sıklı̆̆
}

\author{
A. Avni Atay ${ }^{1}$, Mustafa Tekin ${ }^{2}, K_{\text {Klodian Allajalebeu }}^{2}$, Yonca Eğin², Nejat Akar ${ }^{2}$ \\ ${ }^{1}$ Department of Pediatric Hematology, Gülhane Military Medical Academy, Ankara, Turkey \\ ${ }^{2}$ Department of Pediatric Molecular Genetics, Faculty of Medicine, Ankara University, Ankara, Turkey
}

\section{To the Editor}

Venous thrombosis can be the result of various acquired and genetic factors. Several alterations in the genetics of hemostatic factors that contribute to thrombosis have been described [1]. Inherited anticoagulant protein deficiency-related hypercoagulability is responsible for $5 \%-10 \%$ of all cases of venous thromboembolism (VTE) [2]. An important recognized inherited cause of VTE is resistance to activated protein $\mathrm{C}$ (APC), which is mostly due to a single point mutation in the blood coagulation factor $\mathrm{V}$ gene (G1691A) [3].

Furthermore, a genetic factor that increases the risk of VTE G20210A variation in the prothrombin gene associated with elevated plasma prothrombin level has been described [4].

These 2 genetic prothrombotic factors have heterogeneous geographic distribution patterns. Factor V Leiden and prothrombin G20210A mutation allele frequencies in Europeans are been reported to be $1.4 \%-7.0 \%$ and $3.0 \%$, respectively $[5,6]$. There may be important differences in the allelic frequency of these mutations in different European populations, and they may exhibit regional variations in Europe
[7-10]. The aim of the present study was to determine the frequency of factor $\mathrm{V}$ Leiden and prothrombin G20210A mutations in an Albanian population. Such data may help elucidate the ethnic and/ or geographic differences in the incidence of thrombotic diseases.

We assessed the genetic frequency of the 2 thrombotic risk polymorphisms in a group of 225 randomly selected healthy Albanians, which included a mixture of all cultural groups in Albania, according to a previously reported method [11]. Blood samples were collected at a referral center that serviced people from different regions of Albania. The control group was in Hardy-Weinberg equilibrium. The participants were not chosen from any specific population. The additional members of the same family and those with a family history of any kind of thrombosis were excluded. Written informed consent was obtained from every participant.

Factor V Leiden and prothrombin G20210A prothrombotic alleles are inherited prothrombotic mutations with population-dependent frequencies. Differences in geographic distribution primarily account for regional variation in the incidence of thromboembolism [11]. The high incidence rate in 
Table 1. The prevalence of Factor V Leiden and prothrombin G20210A mutations in an Albanian population

\begin{tabular}{lcccc}
\hline & Total & n & \% & Frequency \\
\hline F V 1691A & 225 & 4 & 1.8 & $4 / 450(0.009)$ \\
PT 20210A & 225 & 7 & 3.1 & $7 / 450(0.016)$ \\
\hline
\end{tabular}

Europeans, as a risk factor for thromboembolic diseases, suggests that screening populations for this mutation is of great importance. The distribution of prothrombin G20210A, the second most frequent prothrombotic polymorphism in humans, has a north-south gradient in Europe. A carrier frequency of $3.0 \%$ has been reported in southern Europe, nearly 2-fold greater than that in northern Europe [6]. It has a very high prevalence in Mediterranean countries. In addition, some microheterogeneity is observed within populations [12].

Factor V Leiden and prothrombin G20210A mutations have not been previously reported in Albanians. To the best of our knowledge this is the first study to examine the frequency of 2 thrombosis-related polymorphisms in healthy Albanians. Factor $\mathrm{V}$ Leiden and prothrombin G20210A mutation was observed in $1.8 \%$ and $3.1 \%$ of the participants, respectively (Table 1 ).

The present study's results show that prothrombin gene 20210GA variation in the Albanian study population did not differ from that reported in other European studies. The 1691GA mutation is not frequent in the Albanian population and its prevalence is similar to that reported from Italy and Spain, and lower than in Greece [13-14].

The present study determined the frequency of 2 thrombophilic polymorphisms in an Albanian population. Determination of the heterogeneity of the prevalence of these 2 common risk factors can help elucidate the geographic differences in the incidence of thromboembolic diseases. Additional research on thrombotic Albanian patients is warranted, as the results may aid in the improvement of evidence-based management.

\section{Conflict of interest statement}

The authors of this paper have no conflicts of interest, including specific financial interests, relationships, and/or affiliations relevant to the subject matter or materials included.

\section{References}

1. Lane DA, Grant GJ. Role of hemostatic gene polymorphisms in venous and arterial thrombotic disease, Blood 2000;95:1517-32.

2. Heijboer H, Brandjes DP, Buller HR, Sturk A, Ten Cate JW. Deficiencies of coagulation-inhibiting and fibrinolytic proteins in outpatients with deep-vein thrombosis. N Engl Med 1990;323:1512-6.

3. Dahlback B, Carlsson M, Svensson PJ. Familial thrombophilia due to a previously unrecognized mechanism characterized by poor anticoagulant response to activated protein $\mathrm{C}$ : prediction of a cofactor to activated protein C. Proc Natl Acad Sci USA 1993;90:1004-8.

4. Poort SR, Rosendall FR, Reitsma PH, Bertina RM. A common genetic variation in the 3 '-untranslated region of the prothrombin gene is associated with elevated plasma prothrombin levels and an increase in venous thrombosis. Blood 1996;88:3698-703.

5. Rees DC, Cox M, Clegg JB. World Distrubition of factor V Leiden. Lancet 1995;346:1133-4.

6. Rosendall FR. Geographic distribution of the $20210 \mathrm{G}$ to A prothrombin variant. Thromb Haemost 1998;79:706-8.

7. Akar N, Dalgın G, Sözüöz A, Ömürlü K, Cin Ş. Frequency of factor V (1691 G-A) mutation in Turkish population. Thromb Haemost 1997;78:1527-8.

8. Akar N. Factor V 1691 G-A mutation distribution in a healthy Turkish population. Turk J Hematol 2009;26:9-11.

9. Akar N, Mısırlıoğlu M, Akar E, Avcu F, Yalçın A, Sözüöz A. Prothrombin gene 20210 G-A mutation in the Turkish population. Am J Hematol 1998;58:249.

10. Bauduer F, Lacombe D. Factor V Leiden, prothrombin 20210A, methylenetetrahydrofolate reductase 677T, and population genetics. Mol Genet Metab. 2005;86:91-9.

11. Akar N. Molecular biology for clinicians: Site specific mutagenesis: Usage for the mutation detection in thrombosis. Turk J Hematol 1998;15:123-4.

12. García-Gala JM, Alvarez V, Pinto CR, Soto I, Urgellés MF, Menéndez MJ, Carracedo C, López-Larrea C, Coto E. Factor V Leiden (R506Q) and risk of venous thromboembolism: a case-control study based on the Spanish population. Clin Genet 1997;52:206-10.

13. Mannucci PM, Duca F, Peyvandi F, et al. Frequency of factor V Arg506 Gln in Italians. Tromb Haemost 1996;75:694.

14. Antoniadi T, Hatzis T, Kroupis C, et al. Prevalence of factor V Leiden, prothrombin G20210A, and MTHFR C677T mutations in a Greek population of blood donors. Am J Hematol 1999;61:265-7. 